\title{
Stock Market Dynamics, Leveraged Network-Based Financial Accelerator and Monetary Policy
}

\author{
Luca Riccetti*1, Alberto Russo $^{2}$, and Mauro Gallegati ${ }^{2}$ \\ ${ }^{1}$ Sapienza Università di Roma, via del Castro Laurenziano 9, \\ 00161 Roma, Italy \\ ${ }^{2}$ Università Politecnica delle Marche, piazzale Martelli 8, 60121 \\ Ancona, Italy
}

\begin{abstract}
We build an agent-based model with a threefold financial accelerator: (i) leverage - negative shocks on firms' output make banks less willing to loan funds, and firms less willing to invest, hence a credit reduction follows further reducing the output; (ii) stock market - due to lower profit, firms' capitalization on the stock market decreases, thus the distance-to-default diminishes and it reinforces the leverage accelerator; (iii) network - credit network may propagate the initial shock. We find that stock market volatility may damage the real economy if the stock market is too relevant. Our findings have relevant implications for monetary policy.
\end{abstract}

Keywords: Agent-based modeling, stock market, leverage, financial accelerator, monetary policy.

JEL classification codes: C63, E32, E52, G01.

\footnotetext{
${ }^{*}$ Corresponding author.

E-mail addresses:_ luca.riccetti@uniroma1.it,_alberto.russo@univpm.it, mauro.gallegati@univpm.it.
} 


\section{Introduction}

The current crisis is showing how business cycle fluctuations can be enlarged by different self-reinforcing mechanisms. Riccetti et al. (2013) consider a twofold financial accelerator, composed by the "leverage" and the "networkbased" accelerators. The former explains that a negative shock on firms' output make banks less willing to loan funds, with a consequent credit constraint and an increase of the interest rate; furthermore, firms are less prone to invest because they compare a reduced expected profit with an increased cost of funding; therefore, the reduced investments lead again to a lower output in a vicious circle. The network-based financial accelerator (Delli Gatti et al., 2010) highlights that the presence of a credit network may produce an avalanche of firms' bankruptcies: the bankruptcy of a firm may bring "bad debt" that affects the net worth of banks, which can also go bankrupt or, if they manage to survive, they will react to the deterioration of the net worth increasing the interest rate to all their borrowers (Stiglitz and Greenwald, 2003, p.145), making them incur additional difficulties in servicing debt and thus increasing the weakness of the whole non-financial sector, in another vicious circle. In addition, Bernanke and Gertler $(1989,1990,1995)$ and Bernanke et al. (1999) show the presence of another positive feedback mechanism: a reduction of asset values held by the entrepreneurs generates an increase of the borrowers' leverage and, subsequently, of the risk premium with a consequent reduction of the economic activity; in our speech, there is a strengthening of the "leverage accelerator". The asset we consider in our analysis is the stock market value of firms' equity, therefore we call this mechanism the "stock market" financial accelerator.

Indeed, starting from Delli Gatti et al. (2010) and Riccetti et al. (2013), in this paper we build an agent based macroeconomic model that also considers the presence of the stock market, although it is added in a stylized way. As in Riccetti et al. (2013), the firms' financial structure relies upon the Dynamic Trade-Off theory. For a review on the Dynamic Trade-Off theory, see for instance Flannery and Rangan (2006), Frank and Goyal (2008 and 2015) and Riccetti et al. (2013). Following this theory we assume that firms have a "target leverage", implying that a growing firm decides to increase its debt level, thus creating in good periods the basis for the subsequent crisis. In this setting, we also consider the loss given default rate (LGDR) - see Section 4 - that is important because it is one of the components, with the probability of default (PD) and the exposure at default (EAD), of the credit risk models. Moreover, we set the firms' stock market value by using the earning-per-share (EPS) multiplier, consistent with the dividend discount model. Stock market values influence the distance-to-default (DD), a measure of credit risk widely 
used by many banks and developed in the Moody's KMV Portfolio Manager model. We use a proxy of the DD, based on stock market return and return's variance, to evaluate firms' financial soundness and, thus, to set the interest rates charged by banks to them. Moreover, we add a risk aversion parameter able to modulate the impact of stock market volatility on firms' DD evaluation. Therefore, we build a methodology in which the agent-based approach, used for modeling the credit market, interacts with some stylized mechanisms, used to represent some features of the stock market, based on techniques derived from the mainstream literature. In other words, beyond the specific conclusions of our simulations, the paper contribution to the existing literature is twofold:

- theoretically, we describe a triple financial accelerator, adding the "stock market accelerator";

- methodologically, we insert in an agent-based model some simple mechanisms, well known in mainstream literature, able to describe some empirical features, such as the relationship between profits and stock market values or the relationship between stock market values and monetary policy.

Instead, regarding the output of the simulations, our model allows to analyze:

- how a shock on the real side of the economy can be amplified, through the stock market multiplier, further increasing the financial accelerator mechanism and the overall fragility of the system. In other words, the interplay between forward-looking evaluation of firms' future profits provided by the stock market and the interest rate setting due to bank lending attitudes may lead to a boom-bust cycle;

- whether a shock on the financial market may be dangerous for the real economy; indeed, we investigate the evolution of the economic environment when the stock market multiplier increases - considered as a symptom of a mounting financial market bubble - in order to ascertain if this results in a riskier systemic configuration;

- how banks' risk aversion can influence the economic environment;

- how the central bank can influence the economic cycle modifying the interest rate; indeed, the interplay between the interest rate and the stock market evaluation can modify the effectiveness of monetary policy, compared to the case in which the stock market is absent (or non relevant). 
The remainder of the paper is organized as follows: in the next Section we present the characteristics of our model. Then, firms' behavior is analyzed in Section 3, while Section 4 considers the banking sector. Simulation results are presented in section 5. A sensitivity analysis on two important parameters regarding the stock market is developed in Section 6. In Section 7 we propose an extension of the baseline model and a monetary policy experiment. Section 8 concludes.

\section{Environment}

Our economy is populated by households (final consumers and labor suppliers), firms and banks. Firms - indexed by $i=1,2, \ldots, I$ - produce consumption goods. Banks, indexed by $z=1,2, \ldots, Z$, extend credit to firms.

We consider three markets: consumption goods, stock and credit markets. We will focus on the last market, making simplifying assumptions for the first and second ones. Moreover, we do not explicitly model the labor market ${ }^{1}$.

On the market for consumption goods there are consumers and firms. Prices are exogenously determined: following Greenwald and Stiglitz (1993), we assume that on the market for consumption goods, prices are governed by a random process. We suppose that consumers buy all the output that firms produce at the stochastic price. Prices on good market have the important role of determining profits, which in turn affect the accumulation of net worth and financial fragility.

In the stock market we take firm prices determined by using the earningper-share (EPS) multiplier. These values influence the evaluation of firms' financial soundness made by banks and, thus, influence the interest rates.

The credit market is the focus of the model, where firms and banks interact. The net worth of firms is the "engine" of fluctuations for the economy: we assume that the scale of production of firms is constrained only by their net worth, then it turns out to be the main driver of fluctuations. A shock to a firm affects the credit relationship between the firm and the bank: if the shock is large enough, the firm may be unable to fulfill debt commitments and may go bankrupt. In a networked economy, the bankruptcy of a firm may bring "bad debt" - i.e. non-performing loans - that affects the net worth of banks, which can also go bankrupt or, if they manage to survive, will react to the deterioration of their net worth increasing the interest rate to all their borrowers. Hence, borrowers may incur additional difficulties in servicing

\footnotetext{
${ }^{1}$ The lack of this market does not change the theoretical framework compared to a model where the labor market is present, workers obtain a fixed slice of aggregate income and entrepreneurs set a mark-up on the labor cost.
} 
debt thus increasing the weakness of the whole non-financial sector and the number of bankruptcies itself (network-based financial accelerator).

The endogenous evolution of credit interlinkages affects the extent of bankruptcies' diffusion: the bankruptcy of a highly connected agent increases the probability of bankruptcy diffusion across the network. The structure of the network of credit relationships evolves endogenously because in every period each firm looks (myopically) for the bank with the lowest interest rate.

\section{Firms}

Firms operates on all the three considered markets.

\subsection{Goods market}

On the market for consumption goods there are consumers and firms. Prices are determined following Greenwald and Stiglitz (1993): we suppose that consumers buy all the output that firms produce at the stochastic price. The output produced by firm $i$ is $Y_{i, t}$ and, following Delli Gatti et al. (2010), it is an increasing concave function of its net worth $A_{i, t}$. Indeed, we assume that the production function (called "financially constrained output function", because $\beta$ is less than 1 ) is:

$$
Y_{i, t}=\phi K_{i, t}^{\beta}
$$

where $\phi>1$ and $0<\beta<1$ are parameters uniform across firms and $K_{i, t}$ is the total capital of the $i$ firm at time $t$, composed by the sum of net worth and debt $B_{i, t} . Y_{i, t}$ is a function of $A_{i, t}$ given that, following the Dynamic Trade-off theory for firms' capital structure, we assume that the amount of debt is a function of the net worth too.

According to the Dynamic Trade-off theory, firms have long-run leverage targets, but they do not immediately reach them, instead they adjust toward them during some periods. The leverage level is set by firms by following an adaptive behavioral rule according to which the current leverage level is equal to the previous level modified by a random percentage increase (decrease) when the expected price $p_{i, t}^{e}$ is larger (smaller) than the expected interest rate on bank loans $r_{i, t}^{e}$ :

$$
\text { Leverage }_{i, t}=\text { Leverage }_{i, t-1}(1 \pm \operatorname{adj} \cdot \text { random })
$$

where $a d j$ is a parameter that set the maximum leverage change between the two periods and is multiplied by a random number drawn by a uniform distribution between 0 and 1 . The sign is + if $p_{i, t}^{e}>r_{i, t}^{e}$ and it is - otherwise. 
Here $p_{i, t}^{e}$ and $r_{i, t}^{e}$ are set adaptively, that is equal to the price and to the interest rate of the previous period. Therefore, the leverage level changes among firms and over time given the evolution of $p_{i, t}$ and $r_{i, t}$. Moreover, the leverage level cannot be set below a $1 \%$ level.

A target debt $B_{i, t}^{*}$ follows:

$$
B_{i, t}^{*}=A_{i, t} \text { Leverage }_{i, t}
$$

As in Riccetti et al. (2013), we assume that debt last for two periods and every period each firm asks for an amount of debt equal to the difference between the target debt and the residual amount of debt $B_{i, t-1}$ made in the previous period (and that will expire in period $t+1$ ):

$$
B_{i, t}=\max \left(B_{i, t}^{*}-B_{i, t-1}, 0\right)
$$

If a firm suffers high losses that, reducing the net worth, make the debt target smaller than the previous debt, then the firm does not ask for new debt. We assume that the nominal debt requested at time $t$ is fully reimbursed at time $t+2$, while interest on the debt is paid both at time $t+1$ and $t+2$. Accordingly, if a firm asks for a new debt at time $t+1$ (in order to match the new target debt), it will fully reimburse this new debt at time $t+3$, and so on.

With these assumptions, we address three issues: (i) firms prefer multiperiodal debt; (ii) firms may have two different banks to obtain credit (in practice big firms often have syndicated loans or multiple banks) and this is another factor able to spread the financial instability in the network; (iii) as implied by the Dynamic Trade-off theory, firms that suffer high losses may present a real debt higher than that implied by the current target (because now the target is lower than the previous period debt) and this rigidity may cause financial problems to firms.

The total capital is consequently calculated:

$$
K_{i, t}=A_{i, t}+B_{i, t}+B_{i, t-1}
$$

Firms' profit is calculated at the end of each period and is given by the following equation:

$$
\operatorname{Pr}_{i, t}=p_{i, t} Y_{i, t}-r_{i, t} B_{i, t}-r_{i, t-1} B_{i, t-1}
$$

where $Y_{i, t}$ is the output, $r_{i, t}$ is the interest rate paid on the last loan $\left(B_{i, t}\right)$, $r_{i, t-1}$ is the interest rate paid on the previous period loan $\left(B_{i, t-1}\right)$, and $p_{i, t}$ is the stochastic gain per unit of output, that contains the stochastic price net 
of the expenses for producing the output itself (but for financial costs). The rationale is the same explained in Delli Gatti et al. (2010): given the predetermined supply, the relative price is an increasing function of the demand disturbance. A high realization of $p_{i, t}$ can be thought of as a regime of high demand which drives up the relative price of the commodity in question. On the other hand, in a regime of low demand, the realization of $p_{i, t}$ turns out to be low and may push the firm to the bankruptcy. In practice $p_{i, t}$ is composed by three parts:

$$
p_{i, t}=\alpha+\frac{\operatorname{Div}_{t-1}+c \cdot A_{z, t-1}-A_{i, t}^{\text {new }}-A_{z, t}^{\text {new }}}{Y_{t-1}}+g_{i, t}
$$

where

- $\alpha>0$ represents an exogenous and positive component of the profit;

- $\left(\right.$ Div $\left._{t-1}+c \cdot A_{z, t-1}-A_{i, t}^{\text {new }}-A_{z, t}^{\text {new }}\right) / Y_{t-1}$ is an endogenous term of the profit, that is an aggregate demand component influenced by the business cycle. It increases the aggregate demand if the previous period aggregate dividends $D i v_{t-1}$ or costs paid by banks $\left(c \cdot A_{z, t-1}\right.$, see also Section 4.2$)^{2}$ increases and it decreases the demand if agents go bankrupt because part of the total income has to be spent to replace the defaulted firms and banks with new firms and banks that require an initial net worth, $A_{i, t}^{\text {new }}, A_{z, t}^{\text {new }}$;

- $g_{i, t}$ is the firm's specific random component. We assume that the random term is distributed as a Gaussian with zero mean and finite variance (varp).

Profits $\left(P r_{i, t}\right)$ are a key component of the model for two reasons. First, they determine firms' net worth $A_{i, t}: A_{i, t+1}=A_{i, t}+P r_{i, t}-D i v_{i, t}$, where only firms with net worth larger than 1 distribute a fraction div of positive profits as dividends $D i v_{i, t}$. The firm goes bankrupt if $A_{i, t+1}<0$, i.e. if it incurs a loss (negative profit) and the loss is big enough to deplete net worth: $\operatorname{Pr}_{i, t}<=-A_{i, t}$; when a firm goes bankrupt, we assume that a new firm enters in the market with a small random net worth. Second, profits determine the earning-per-share (EPS) used in the evaluation of the firms' market value in the stock market, that we will now analyze.

\footnotetext{
${ }^{2}$ We assume that the costs paid by banks are an income for the household sector, which spends such an income to consume final goods.
} 


\subsection{Stock market}

We set the firms' stock market price as a long run value. Thus, we focus on the so-called fundamentalist investors (with a long investment horizon), avoiding chartist trader effects. Then, we use the earning-per-share (EPS) multiplier, that is the technique most used by the fundamentalists, and the accounting value, as proxy for all the other fundamentalist techniques. In particular, the market value is set in the following way:

$$
A m k t_{i, t}=0.5 \cdot A_{i, t}+0.5 \cdot \max \left(P r_{i, t-1} \cdot \operatorname{moltp}, 0\right)
$$

where moltp is the EPS multiplier ${ }^{3}$.

We have adopted a basic price mechanism, without a real modeling of the stock market for the sake of simplicity. We will relax these assumptions in further extensions of the present model, considering the criticism made in the field of behavioral finance and modeled by many agent based models, that shows that deviations from the "fair price" are common and caused simply, for instance, by the presence of chartist traders or by herding behavior (as an example of this large literature strands, see Tedeschi et al., 2012). However, EPS multiplier practice is also grounded on the dividend discount model: the price of an asset is determined by the expected dividend supposed to be generated for all the future history of the firm and discounted with the rate representative of the firm's cost of capital, that is composed by the risk free rate plus a risk premium (often based on the capital asset pricing model) ${ }^{4}$. In line with the practice in financial markets, fundamentalists use the earnings and not the dividends, because the fraction of not distributed earnings is retained in firms' net worth and then reinvested in firms' production. This should generate an increase in the future flow of profits (and consequently dividends) that fundamentalists incorporate in their behavioral rule based on the EPS multiplier.

The stock market values influence the evaluation of firms' financial soundness made by banks and, thus, influence the interest rates.

We assume that the stock market is not used for the initial public offering (IPO) or to issue/buy-back new securities, then it is just a secondary market. Thus, firms can finance themselves only by self-financing and bank credit.

\footnotetext{
${ }^{3}$ We use the max function because the value of the profits can be negative enough to make the overall market value negative. This is a simplifying assumption. In fact, fundamental analysts put beside EPS multiplier other multipliers in order to prevent negative stock price forecast driven by negative profits.

${ }^{4}$ The most famous dividend discount model is the Gordon (1959) model. The Gordon model is based on the assumptions of a never-ending dividend, of a constant growth rate of the dividend and a constant cost of equity capital (larger that the growth rate of the dividend).
} 


\subsection{Credit market}

In this market firms and banks interact. In every period each firm asks for a debt that lasts two periods as explained before. Initially, firm-bank links are set randomly. Afterwards, in every period each borrower observes the interest rates of a fraction $\chi$ of randomly selected banks. We assume, as done in Delli Gatti et al. (2010), that the firm changes bank with a probability ps of switching to the new lender that increases (in a non-linear way) when $r_{n e w}$ (the interest rate set by the observed potential new bank) lowers compared to $r_{\text {old }}$ (the previous bank's interest rate):

$$
p s=1-e^{\lambda\left(r_{\text {new }}-r_{\text {old }}\right) / r_{\text {new }}}
$$

In this way, we model the sticky connection between a borrower and its banks, due to the (asymmetric) information on the firm owned by the banks. An increasing parameter $\lambda>0$ represents a growing propensity of switching from a bank to another according to the best interest rate. In this way the structure of the network of credit relationships evolves endogenously due to a decentralized mechanism of interaction. Thus, prices on the credit market (that is, interest rates) have two important roles: (i) they influence profits, which affect both net worth accumulation and financial fragility, (ii) they shape the evolving topology of the credit network. Indeed, financially sound banks may charge lower prices thus attracting new partners. As a consequence, their profits go up and their financial conditions improve, making room for even lower interest rates in the future and more new partners. This self-reinforcing mechanism gives rise to an endogenous evolution of the credit network that will be characterized by a right-skew distribution of node degree: there will be some nodes characterized by a relatively high number of links ("hubs") and a majority of nodes with a small number of connections. Higher values of parameters $\lambda$ and $\chi$ increase the banking sector concentration. We calibrate the value of the parameter $\lambda$ in order to obtain a banks' degree distribution similar to the real Japanese one at year 2000, thus we set $\lambda=4$ (for the calibration procedure, see Bargigli et al., 2014).

Moreover, we add a fixed commission equal to the $1 \%$ of the expiring debt if the firm changes the partner bank, as a proxy for information and administrative costs. In order to complete the description of the credit market, we need to explain how banks set the interest rate, then we now introduce banks. 


\section{Banks}

\subsection{Interest rate setting}

As said above, we assume that the stock market works as a secondary market, thus firms can finance production only by self-financing and bank credit.

Moreover, every bank sets a different interest rate on loans and these spreads imply that firms sometimes change banks to obtain a lower interest rate, following the mechanism explained in Section 3.3. We assume that bank $z$ adopts the following rule in setting the interest rate on loans to borrower $i$ :

$$
r_{i, t}=r C B_{t}+f 1\left(A_{z, t}, D_{z, t}\right)+f 2\left(D D_{i, t}, A_{i, t}\right)
$$

Thus the interest rate is composed of three parts:

1. the policy rate set by the central bank: $r C B_{t}$;

2. a term that decreases with the financial soundness of the bank (proxied by the inverse of bank's leverage). Indeed, as already said, if the bank is in good shape from the financial point of view, it will be eager to extend credit at more favorable terms to increase its market share. We set this term as follows:

$$
f 1\left(A_{z, t}, D_{z, t}\right)=\left(\frac{A_{z, t}+D_{z, t}}{A_{z, t}}\right)^{\gamma}-1
$$

where $D_{z, t}$ is the amount of deposits that bank $z$ has at time $t$, calculated as the difference between extended credit and net worth, while $\gamma>0$ is a risk premium parameter;

3. a term that incorporates a risk premium decreasing with borrower's Distance to Default $\left(D D_{i, t}\right)$, that we will analyze hereafter, and decreasing for larger firms. Thus, we set:

$$
f 2\left(D D_{i, t}, A_{i, t}\right)=\gamma \cdot \frac{\left(B_{i, t}+B_{i, t-1}\right)}{\left[\text { weight } \cdot \frac{A m k t_{i, t}}{\sigma_{i, t}^{1 / \psi}}+(1-\text { weight }) \cdot A_{i, t}\right]} \cdot \frac{1}{\left(1+\frac{A_{i, t}}{A_{i, t}^{m, a x}}\right)}
$$

Equation 12 is a proxy of the inverse relationship between the DD and the risk premium, because the risk premium declines as the stock market value Amkt increases or the stock market return volatility $\sigma$ decreases ( $\sigma$ is equal to 1 plus the standard deviation of the firm's assets market value calculated on the last TT periods ${ }^{5}$ divided by 100).

\footnotetext{
firms.

${ }^{5}$ New firms have the standard deviation set at the highest value among the survival
} 
Market volatility evaluation is influenced by a risk propensity parameter $\psi>0$ : when $\psi$ grows, banks are less risk averse, that is less afraid of market volatility, and reduces the interest rates. The parameter weight determines how strong is the stock market component in the firm evaluation ranging from 0 to 1 (and it could be seen as a presence of a mark-to-market mechanism instead of a balance sheet evaluation): if weight is set at its upper bound, that is 1 , banks only consider the market value, while if it is equal to its lower bound, that is 0 , they only consider the accounting value. $A^{\max }$ is the accounting net worth of the biggest firm, therefore $\left(1+A_{i, t} / A_{i, t}^{\max }\right)$ is a correction so that larger firms obtain lower interest rates (all the other components being equal $)^{6}$.

As for DD, this is a widely used market-based measure of corporate default risk. It was introduced in the Portfolio Manager model developed by the KMV society ${ }^{7}$ that was later acquired by Moody's. Banks widely use measures like the DD, because this is a simple way to introduce in the firm evaluation a forward looking analysis based on the market ability to incorporate firm prospects in the market price. Indeed, a firm with a high stock market capitalization should easily obtain credit from banks, given that the firm may also issue new equities on the stock market to repay previous debts. This is then a sort of collateral.

Many authors find that the DD is an effective method to explain differences in credit spreads; for example Campbell and Taksler (2003) find that equity volatility of corresponding stocks explains as much variation in corporate credit spreads as credit ratings do or, in other words, that equity volatility affects loan ratings.

The DD is derived from the structural evaluation model of corporate debt introduced by Merton (1974) and it is based on the two following features: the higher the value of the firm's net worth or the lower the volatility of the firm's net worth, the further away from default the firm is. The framework is built on an accounting identity: the value of the firm, $V$, (or the value of its assets) should be equal to the sum of the values of its debt, $B$, and equity, Amkt. Here we use $V$ instead of $K$, because $V$ is a market based value of the total assets, while $K$ is a balance sheet value:

$$
V_{i, t}=A m k t_{i, t}+B_{i, t}+B_{i, t-1}
$$

\footnotetext{
${ }^{6}$ The largest firm divides the $f 2$ component of the interest rate by 2 , while the smallest firms divide it by a value near to 1 . The resulting value is multiplied by the risk premium parameter $\gamma>0$.

${ }^{7} \mathrm{KMV}$ from the names of the founders: Kealhofer, McQuown and Vasicek.
} 
Given that debt is senior to equity, equity holders are residual claimants to the firm: firm's assets are first used to pay debt holders, and the left part is distributed to shareholders. Thus the value of equity is:

$$
E_{i, t}=\max \left(0, V_{i, t}-B_{i, t}-B_{i, t-1}\right)
$$

The payoff to shareholders is equivalent to a call option on the value of the firm with a strike price equal to the face value of debt, also known as default barrier. This formula implies that the higher the value of the firm's assets, $V_{i, t}$, relative to the strike price or default barrier, $B_{i, t}+B_{i, t-1}$, the further away from default the firm is. In the case of the widely used Merton (1974) model, where the asset value of the firm are assumed to follow a geometric Brownian motion process, the distance-to-default $T$ periods ahead is given by:

$$
D D_{i, t}=\frac{\ln \frac{V_{i, t}}{B_{i, t}+B_{i, t-1}}+T\left(\mu_{i, t}-\frac{\sigma_{i, t}^{2}}{2}\right)}{\sigma_{i, t} \sqrt{T}}
$$

where $\mu_{i, t}$ and $\sigma_{i, t}$ are respectively the mean and the volatility of the growth rate of firm's asset value $V_{i, t}$. As shown by equation 15 , DD increases when $V_{i, t}$ grows and when the volatility of asset value reduces. Given that the DD and the risk premium $f 2$ are inversely related, Equation 12 shows that $f 2$ reduces when $A m k t_{i, t}$ (and therefore $V_{i, t}$ ) increases or $\sigma_{i, t}$ decreases. Moreover, as already said, we compute the growth volatility using the value of $V_{i, t}$ of the last TT periods.

In this model we insert the stock market influence on banks only indirectly, through the distance-to-default mechanism. In fact, universal banks can suffer from stock market volatility because they directly invest part of their capital in stocks (trading book). So our findings could be enriched by this channel, that we will investigate in an extended version of the model.

\subsection{Banks profit and net worth}

Banks' net worth $A_{i, t}$ evolves in the following way:

$$
A_{z, t+1}=A_{z, t}+\operatorname{Pr}_{z, t}
$$

where $P r_{z, t}$ is bank $z$ profit at time $t$, given by:

$$
P r_{z, t}=\sum r_{i, t} B_{i, t}+\sum r_{i, t-1} B_{i, t-1}-r C B_{t} \cdot D_{z, t}-c \cdot A_{z, t}-b a d_{z, t}
$$

where $r_{i, t}$ is the interest rate paid on the credit $B_{i, t}$ (if firm $i$ has not gone bankrupt), $r C B_{t}$ is the Central Bank official interest rate, that we assume to 
be also the interest rate paid by bank $z$ on its deposits $D_{z, t}, c$ is a fixed cost paid by every bank depending on its size (proxied by the net worth), and $b a d_{z, t}$ is the bad debt of the bank. In particular, $b a d_{z, t}$ is computed as the sum of all the credit provided to firms defaulted in period $t$, multiplied by the loss given default rate (LGDR), that is 1 less the recovery rate (RR). RR is computed as the ratio between the asset and the debt of the bankrupted firm and decreased by a fixed amount for the legal expenditure LE (that, in the baseline model, we assume equal to $10 \%$ of the debt). In this way we insert both the two most important components of the credit risk models: the probability of default (PD) and the loss given default rate (LGDR).

\section{Simulations}

We analyze our economy by means of computer simulations. We assume that this economy is composed by 500 firms and 50 banks over a time span of 1000 periods. However, we use the first 200 periods to initialize the simulation, therefore we present the last 800 periods only.

At the beginning of the simulation, we set the net worth of each firm and bank to 10. We assume that when a firm or a bank goes bankrupt it is replaced by a new one with net worth equal to a random number between 0 and 2 for firms and between 0 and 10 for banks. The parameter used are in Table 1.

Table 1: Parameter setting.

\begin{tabular}{l|c|l} 
Parameter & Value & Meaning \\
\hline$\phi$ & 2 & see production function eq.1 \\
$\beta$ & 0.8 & see production function eq.1 \\
$\alpha$ & $5 \%$ & expected mark-up, see eq.7 \\
varp & 0.1 & profit variance, see eq.7 \\
div & $20 \%$ & percentage of profits distributed as dividends \\
moltp & 20 & EPS multiplier, see eq.8 \\
adj & $20 \%$ & max leverage change allowed to firms in one period, see eq.2 \\
$r C B$ & $2 \%$ & central bank monetary policy rate, see eq.10 \\
$\gamma$ & $1 \%$ & risk premium parameter, see eq.11 and eq.12 \\
weight & 1 & \% stock market influence on firm evaluation, see eq.12 \\
$\psi$ & 5 & risk propensity parameter, see eq.12 \\
TT & 5 & periods to calculate st. dev. of market value of firm's assets \\
$c$ & 0.2 & bank operational costs, see eq.17 \\
$\chi$ & $20 \%$ & percentage of bank observed by each firm in every period \\
$\lambda$ & 4 & propensity of switching from a bank to another, see eq.9 \\
LE & $10 \%$ & legal expenditure for firm's bankruptcy, added to LGDR
\end{tabular}


We do not perform a validation exercise, given that we have sketched many characteristics of the economic system and we have neglected some others such as the labor market, even if we calibrate parameter values to reproduce some empirical regularities in the simulated data, as already found in Delli Gatti et al. (2010) or Riccetti et al. (2013). For example, even if all firms start from the same conditions, they become rapidly heterogeneous and a right-skewed distribution of firms' size emerges. This feature also emerges for banks, which concurrently present a right-skewed distribution of the number of borrower firms (the degree distribution of the credit network). However, in Section 6 we perform a sensitivity analysis to show some interesting features related to the different values of model parameters.

As already said, our model extends the analysis of Riccetti et al. (2013) by considering the stock market dynamics. Now, the mechanism of the Networkbased Financial Accelerator is threefold:

1. leverage accelerator. A firm that makes less (or negative) profit, lowers its growth (or its activity), reducing both the amount of internal funds and of external finance. Here we assume that the firm asks less credit, but this characteristic could be theoretically coupled with the unavailability of banks to loan funds to a firm with smaller cash flow and smaller value of firm's collateral. Hence the firm reduces its investment, leading to a lower output, a lower profit, and yet again lower investment. In other words, there is a leverage cycle that enlarges business fluctuations, as shown in the upper right plot of Fig.2: when net worth increases, leverage increases boosting the production (positive correlation on the left side of the cross-correlogram), but after a while this leads to growing instability that will revert the business cycle (negative correlation on the right side of the cross-correlogram);

2. stock market accelerator. After lower profits, the firm's capitalization on the stock market decreases; thus DD reduces and banks charge a higher interest rate. This further reduces the firm's profit, boosting the previous mechanism. Hence, the presence of the stock market amplifies the leverage financial accelerator mechanism, given that the interest rate is set following a profit multiplier. Moreover, just a small reduction of profits can trigger this financial accelerator ${ }^{8}$. We study the ratio between stock market capitalization and balance sheet net

${ }^{8}$ For example, in year $t$ a firm has a total capital of 20, composed by 10 of net worth and 10 of debt $\left(K_{i, t}=A_{i, t}+B_{i, t}\right)$, a profit of 3 and, with a multiplier of 20, a market capitalization of $35(0.5 \cdot 20 \cdot 3+0.5 \cdot 10)$; the next year the firm makes again a positive profit of 2 and net worth increases to 12, but the market capitalization decreases from 35 to 26 , with a $-26 \%$ of return that reduces the distance to default and increases the interest 
worth (we call it capitalization ratio): when it grows, overall output level grows but after a while the output tends to decrease, because there is an increasing probability of trigger the explained mechanism. In this way we represent the possible creation of a bubble and the subsequent crisis. Indeed, the cross-correlation between the capitalization ratio and the number of bankruptcies shows that a bubble increases the probability of a crisis: the growth of this ratio is related with following firm and bank defaults rise, as shown in the bottom plots of Fig.1;

3. network-based accelerator. A firm could even not be able to pay its debt to banks and goes bankrupt. Partner banks record a nonperforming loan that reduces their net worth. If banks are not financially robust, they could also go bankrupt. Instead, if the loan is relatively small compared to the banks' net worth, they survive the loss; however, even in this case, banks increase the interest rates to other borrowers to cover the loss; the increased interest rates reduce firms' profit, enacting again the leverage financial accelerator or, if other firms go bankrupt, enlarging the network-based mechanism. In both cases, with or without bank defaults, the initial shock spreads across the financial network, with the possibility to create an avalanche of bankruptcies, which amplifies business fluctuations. In our simulations, financial fragility creates quite strong bankruptcies avalanches with the number of defaulted banks in the same period that is in mean equal to the $0.45 \%$ of the overall number of banks (that is 50 ), but it ranges from a minimum of 0 to a maximum of $8 \%$ of the banks in the economy; moreover, bankruptcies tend to cluster in subsequent periods; the distribution of bank defaults present positive skewness (2.69) and high kurtosis (11.86). However, this propagation could be dampened (or increased) considering the interbank market, that we want to introduce in further extensions of the present model. Bank defaults are triggered by bad debt (firm bankruptcies): correlation coefficient is statistically significant and equal to $54.5 \%$ (Fig.2 panel bottom-right). Analyzing the distribution of firm's bankruptcies, we observe that they vary from a minimum of 4 ( $0.8 \%$ of overall firms) to a maximum of $28(5.6 \%)$, with a mean of 12.78 and a positive skewness of 0.38 .

The first mechanism, as already said, is the leverage financial accelerator; the second mechanism due to the presence of the stock market, that is the innovation of this paper, reinforces the first; the third is the accelerator due to

rate that banks will charge on following credits: the firm becomes to be finacially weaker, even if it is still profitable. 
Figure 1: Cross-correlations between: (i) firms' leverage and firms' defaults; (ii) firms' leverage and banks' defaults; (iii) firms' capitalization ratio (e.g., market values over balance sheet value of firms) and firms' defaults; (iv) firms' capitalization ratio and banks' defaults.

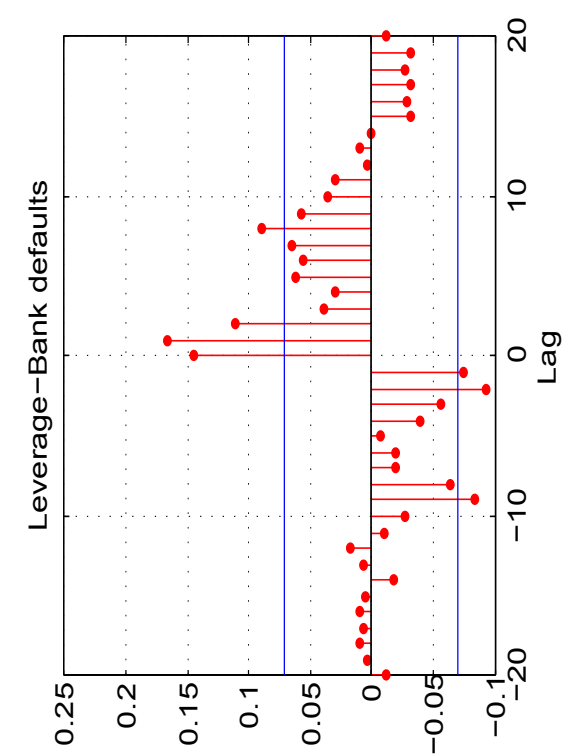

uо!̣e|әมдо ssoıว ә|durs

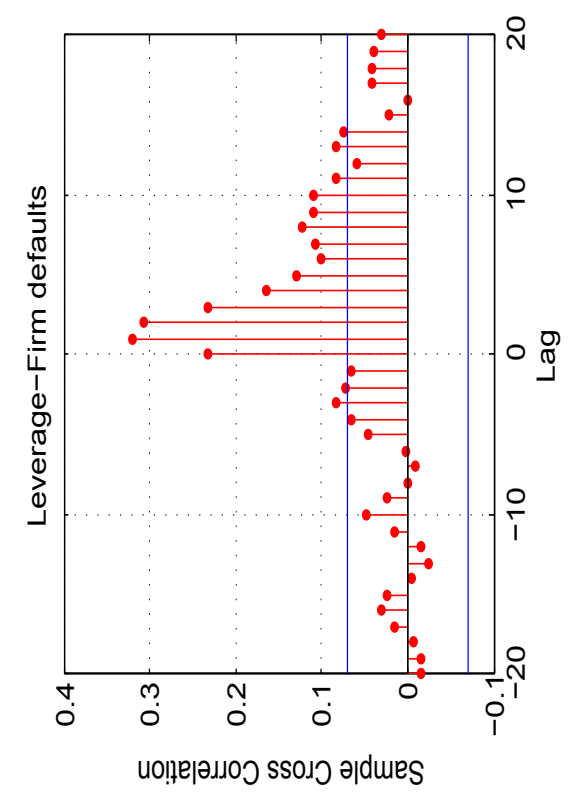

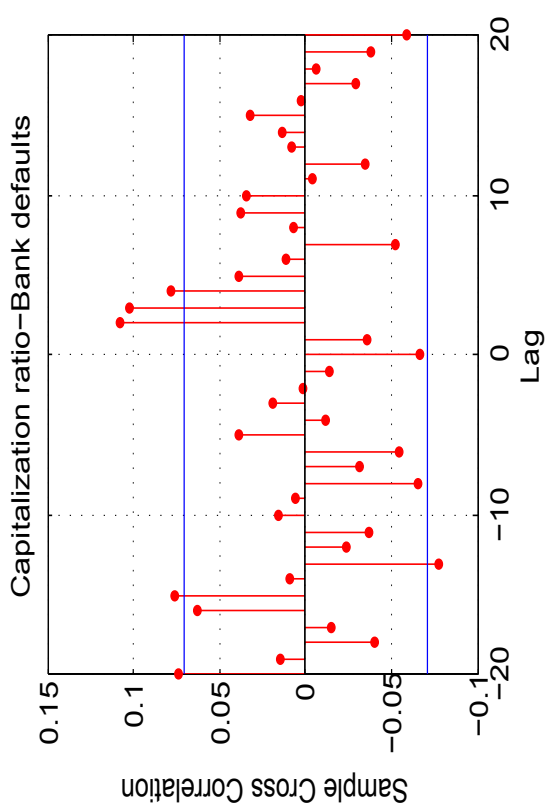

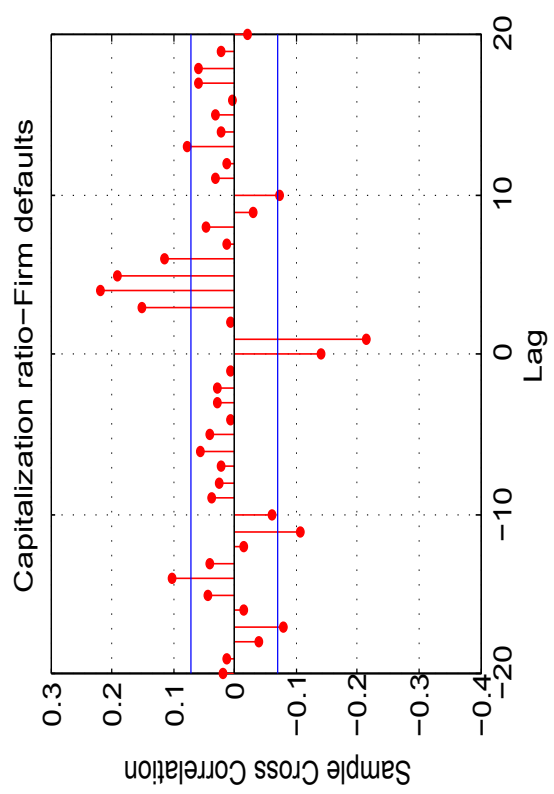


Figure 2: Cross-correlations between: (i) firms' leverage and bad debt ratio (e.g., total bad debt over total credit); (ii) firms' leverage and firms' net worth; (iii) firms' capitalization ratio and firms' leverage; (iv) firms' leverage and mean interest rate; $(v)$ mean interest rate and bad debt ratio; (vi) bad debt ratio and banks' defaults.

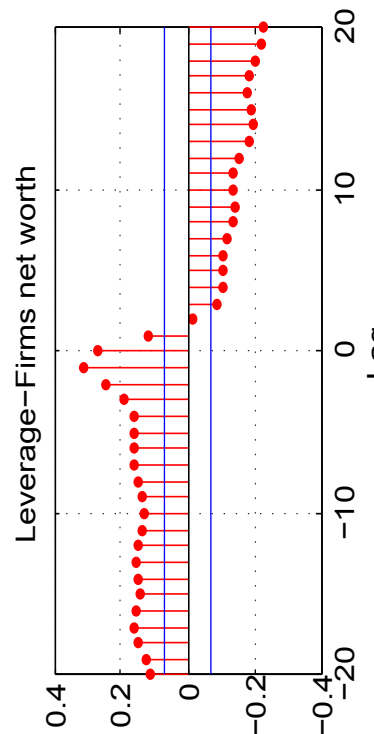

uо!̣e|әגоว ssoגว әрdures

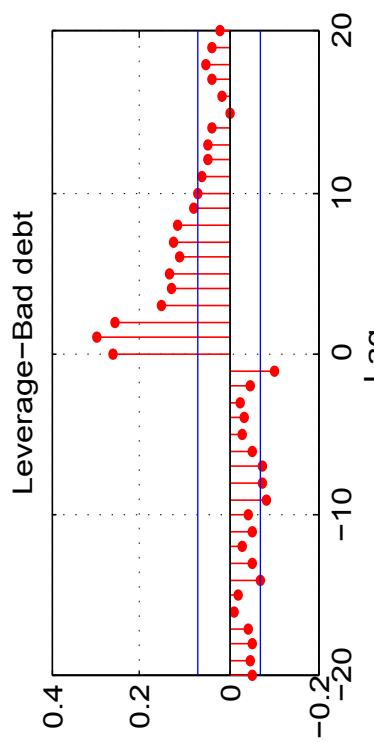

ио!̣e|әдоว ssoљว әрdures

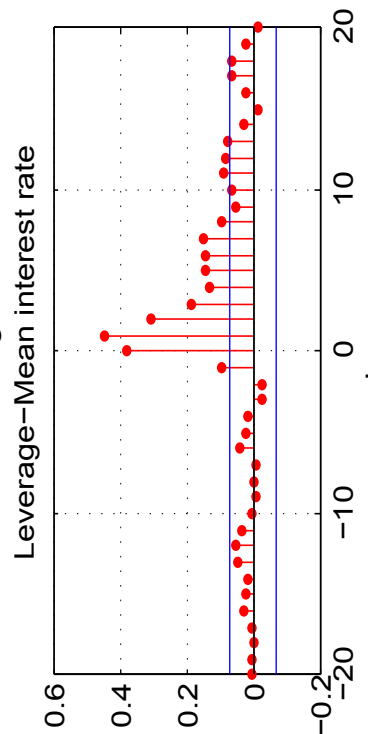

ио!̣e|əגоว ssoљว ә|dues

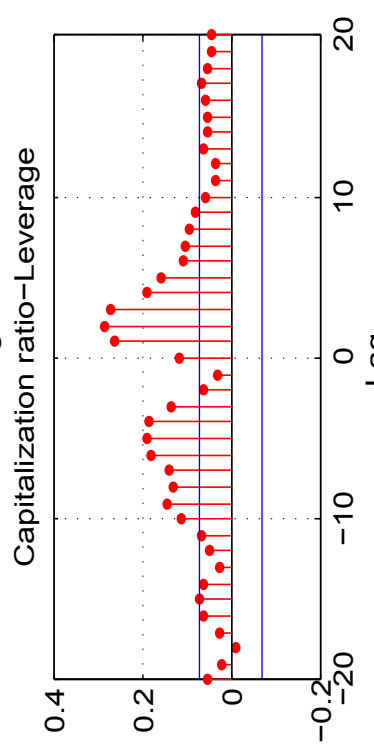

ио!̣е|әцоว ssољว әрdmes
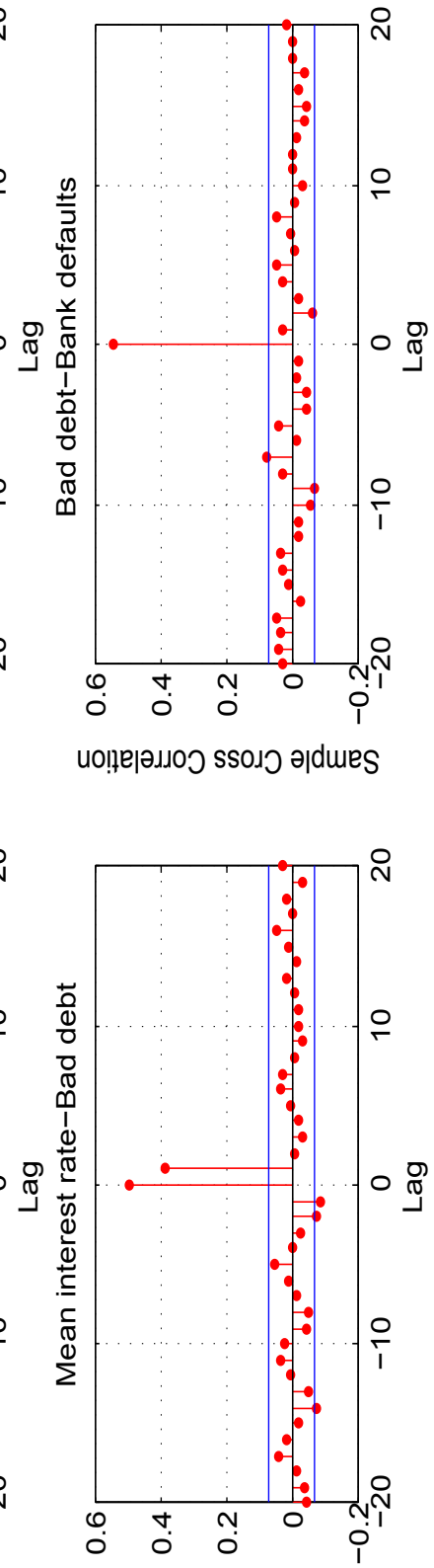

ио!̣е|әдоว ssoљว әрdures 
the network. The first two mechanisms are the trigger of the accelerator, the third makes possible that an idiosyncratic shock creates an extended/global crisis, without the need of a systemic shock. The instability due to the first two accelerators is shown in Figure 1: an increasing firms' leverage or an increasing stock market bubble enlarges the number of subsequent firm and bank's defaults. We can divide the overall causal sequence in many parts, following Figure 2. The leverage accelerator is described in the two upper plots, that show the already explained leverage cycle: when the economy is growing, that is the net worth increases and the bad debt reduces, firms increase their leverage (because of increased expected profits); the high leverage makes the cycle to revert, increasing bad debt and decreasing net worth. Indeed, if leverage grows, banks require a higher interest rate (center-right panel), that reduces firms' gain and increases bankruptcies (bottom-left plot). Firms bankruptcies, through consequent bad debt, increase the number of bank defaults (bottom-right panel). The leverage cycle can be enlarged by the stock market (forward-looking) fluctuations: when the stock market capitalization increases, an interest rate reduction follows causing a higher leverage (positive correlation between capitalization ratio and leverage in the center-left plot) and thus starting or boosting the leverage accelerator mechanism. In other words, the stock market seems to reinforce the leverage cycle.

Till now, we have presented a model with real shocks to firms, that, reducing profits, start the first two mechanism. Now, we can study:

- how the presence of the stock market in the firms' evaluation done by banks affects the output (parameter weight);

- how the stock market volatility affects the real performance of the economy (parameter moltp).

Moreover, in Section 7, we will analyze the influence of the stock market on the monetary policy effectiveness ${ }^{9}$.

\section{Sensitivity analysis}

In this section we discuss the effect of parameter changes weight and moltp in terms of the following output variables: the mean aggregate production, the volatility of the aggregate production's growth rate, the average interest rate, the mean firms' leverage, the average aggregate firms' net worth, the

\footnotetext{
${ }^{9}$ For the sensitivity analysis of most of the other parameters, we refer to Riccetti et al. (2013). Indeed, even if the model is not exactly the same, the qualitative findings of that sensitivity analysis are still valid.
} 
mean number of firms' bankruptcies, the average value of bad debt ratio (the sum of all debts of defaulted firms in the period divided by the overall outstanding credit), the average number of bank defaults. These statistics are calculated, for each simulation, on the time series from period 301 to period 1000 .

\subsection{Parameter weight}

Parameter weight determines the weight of the stock market component in the firm evaluation done by a bank in order to set the interest rate (see Equation 12). The same simulation is repeated for each value of weight between 0 and 1 , with step 0.05. Moreover, we study how the risk aversion of banks modifies the output, comparing the sensitivity analyses for two different values of the risk propensity parameter $\psi$ (that is $\psi=2$ and $\psi=20$ ), keeping all the other parameters unchanged (see Table 1). $\psi$ can represent how confident banks are about the economic cycle and, thus, a lower risk propensity can be associated to a stronger credit constraint phase on credit market. In our model, banks cannot directly invest in the stock market or in derivatives, thus a higher risk aversion does not reduce the investment in speculative assets, but only applies to the credit market.

As shown in Figure 3, when banks are very risk averse $(\psi=2)$, we find that: (i) the mean aggregate production reaches its maximum for low values of weight, that is it slightly increases when the stock market enters in the evaluation of the firm (weight equal to 10\%-15\%), but decreases when this component becomes prevalent; (ii) the volatility of the real aggregate production (measured by the standard deviation of the growth rate) is quite stable; (iii) when weight grows, banks ask for higher and higher interest rates (with a non-linear growth) because the increasing stock market volatility is heavily valued by banks when $\psi$ is low; (iv) the mean leverage follows the opposite shape of the interest rate, given that higher rates imply lower target leverage; (v) the average aggregate net worth has the same shape of the aggregate production (indeed, it is a function of the net worth); (vi) the mean number of firm's bankruptcies is stable from weight $=0$ to weight $=0.7$, and then it slightly reduces thanks to the leverage reduction that makes firms more financially robust; (vii) however, the ratio between the aggregate bad debt (that decreases) and the aggregate extended credit (that reduces even more) increases, because the defaulted firms present a mean leverage largely above the mean leverage of the survived firms; (viii) the number of bank defaults remains almost stable till weight $=0.8$ because the mean interest rate increases and this offsets the higher bad debt ratio, but for weight $>0.8$ defaults tend to increase following the growth of the bad debt ratio. To sum 
Figure 3: Sensitivity analysis for parameter weight, from 0 to 1 with step 0.05. Dotted lines when $\psi=2$ and solid lines when $\psi=20$.
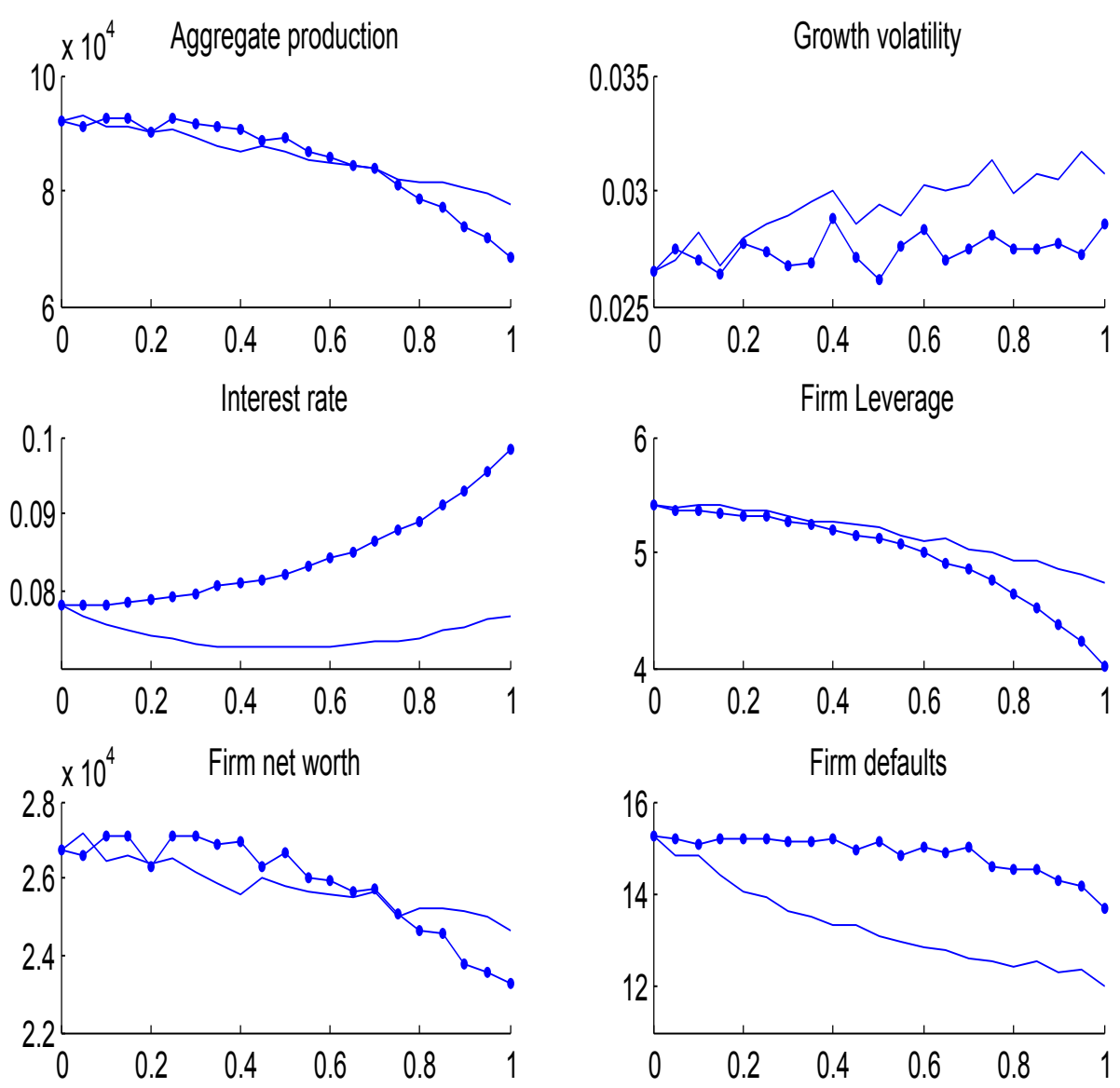

Firm defaults
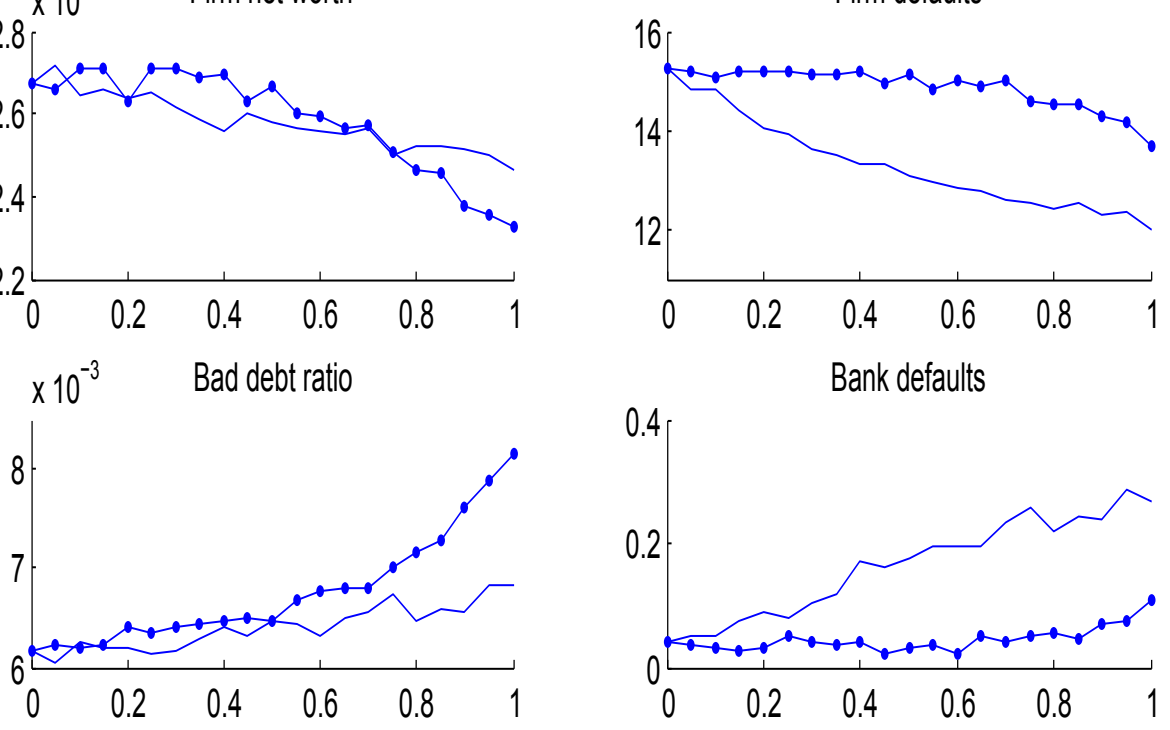
up, for low values of weight, the stock market can sustain the economy, and our result could become even better allowing firms to raise funds in the stock market. Instead, when the stock market is strongly considered by banks in firms' evaluation, its presence reduces the aggregate production. Indeed, when banks are very risk averse, they react to the stock market fluctuations constraining credit (represented in the model by higher interest rates and then lower firms' leverage). This has two consequences: on one hand it prevents the economy to become too volatile, offsetting the volatility effect caused by the stock market fluctuations; on the other hand, however, it reduces the economic activity.

In the other setting, when banks are prone to risk $(\psi=20)$, we find that the interest rate is U-shaped: when the stock market enters in the evaluation it helps in reducing the interest rates compared to the case of no stock market influence (because the market value can be higher than the balance sheet value of the firm, improving the distance-to-default, while the associated increased volatility is barely evaluated by prone to risk banks), but when this influence becomes too relevant and the volatility of the system increases, then firms' stability reduces and banks ask for higher interest rates. As in the previous case: the average aggregate production (and aggregate firms' net worth) reaches its maximum for very low values of weight and then it decreases; firms' leverage reduces and this reduces firms' defaults; but, again, the bad debt ratio increases because the bad debt decreases less than the overall debt, indeed the bankrupted firms have both a growing ratio between mean net worth and mean leverage to average net worth and average leverage of the whole population of firms respectively. Consequently the number of bank defaults increases. Differently from the previous case $(\psi=2)$, the low and more stable interest rates (representing a smaller credit constraint) keep the leverage, and consequently the aggregate production, more stable between low and high values of parameter weight. However, the increased macroeconomic volatility, associated with a stronger stock market accelerator, makes firms' growth more unstable, reducing both firms' net worth and leverage. Moreover, banks are weaker because they do not face the increasing bad debt ratio with growing interest rates.

All in all, we can affirm that a low stock market influence can help the real economy, but if the stock market component is too strong, then the aggregate production reduces, the business cycle volatility increases and the banking system becomes weaker. These fragilities are present both in the case of risk averse and in the case of risk prone banks. Indeed, when the stock market is very relevant, a risk averse banking system constrains the supply of credit and it cools the economy, with a consequent higher bad debt ratio resulting in a growing number of bank defaults, while a risk prone banking system 
subsidizes firms that live in a more unstable environment, resulting in a even riskier economic system (stronger financial accelerator) with again a higher bad debt ratio and number of bank defaults.

\subsection{Parameter moltp}

Now we analyse how the parameter moltp influences the economy. We replicate the simulation for moltp between 5 and 100, with step 5 . All the other parameters are set as in Table 1; thus, parameter weight is equal to 1 and the stock market volatility widely affects the determination of the interest rate through the DD. The parameter moltp has a strong influence in determining the volatility of the stock market. For example, a high moltp can represent a stock market bubble, that also increases the market volatility. In other words, a high multiplier increases the stock market capitalization and, thus, the ratio between market capitalization and balance sheet net worth (the capitalization ratio), that also becomes much more volatile. When the EPS multiplier increases, the most important features shown in Figure 4 are: (i) the mean aggregate production reduces; (ii) the volatility of the real aggregate production growth rate rises; (iii) the interest rate firstly falls, given that the stock market increases the firms' value, but then stabilizes, because the stock market bubble makes the firms' value more volatile, reducing the $\mathrm{DD}^{10}$; (iv) the mean leverage, even if the interest rate declines, decreases because the overall economy is weaker and the expected profit reduces; (v) firm defaults decrease because leverage decreases, but (vi) bad debt ratio grows because the average size of defaulted firms raises and, consequently, the bad debt declines less than the overall outstanding debt; (viii) bank defaults sharply rise, because of the interest rate fall and of the bad debt ratio growth. To sum up, when there is a highly volatile stock market the economy is weaker, more volatile and the banking system is more fragile. The increasing economic fragility has strong monetary policy implications, as we will see in the next Section.

We conclude that financial shocks, for example a mounting stock market bubble, can create real economic effects enlarging business fluctuations and

\footnotetext{
${ }^{10}$ We repeat the simulation for different values of the risk propensity parameter $\psi$. The only remarkable difference concerns the interest rate: for $\psi=2$, the interest rates are higher and are U-shaped when moltp increases; instead, when $\psi=20$, the average interest rates are lower and always decreasing as moltp increases. This is obvious: if $\psi$ is low, when the stock market grows the DD initially enlarges and, subsequently, the DD reduces because banks negatively evaluate the capitalization volatility that becomes too ample. Instead, when banks are very risk-prone, the growing market capitalization has an effect on the DD larger than the effect of the growing volatility, thus DD increases, making room for lower interest rates.
} 
Figure 4: Sensitivity analysis for parameter moltp, from 5 to 100 with step 5.
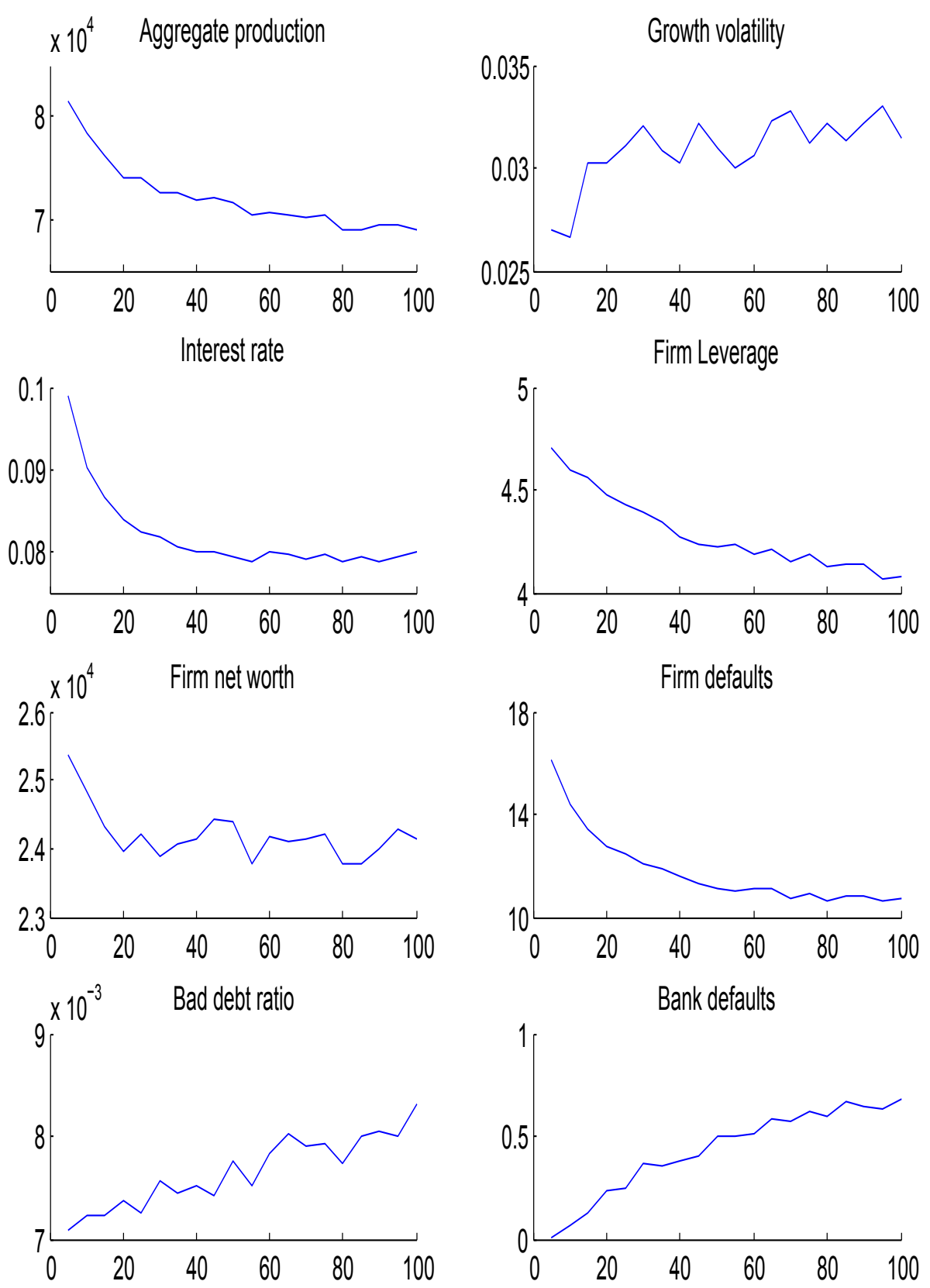
reducing aggregate income.

\section{$7 \quad$ Varying stock market multiplier and mon- etary policy experiment}

In this section we compare the effect of a monetary policy expansion (the opposite holds for a policy rate tightening), that is a reduction of the central bank interest rate from $3 \%$ to $1 \%$ at time 601 , on the baseline model and on a slightly different model - that we call "Multiplier" model - in which the stock market multiplier is affected by the interest rate level. In this second model we calculate the EPS multiplier in the following way, that considers 40 periods of future discounted cash flows ${ }^{11}$ :

$$
\operatorname{moltp}_{t}=\sum_{i=1}^{40} \frac{1}{\left(1+r C B_{t}\right)^{i}}
$$

Among the causes at the basis of an increase of the stock market multiplier when the monetary policy rate decreases there is, for instance, the low profitability of monetary and bond products that results in a liquidity inflow into the stock market. This is analytically represented in the above formula through a smaller discount rate.

We replicate the comparison of the effect of a monetary policy between the baseline and the "Multiplier" model, for two different level of risk aversion $\psi=2$ (high risk aversion) and $\psi=20$ (low risk aversion).

We start with the case of $\psi=2$, represented in Figure 5 and 6 . In the baseline model, when the policy rate decreases, the investments increase driven by a higher leverage (center-left plot of Figure 6) and a short-run expansion of aggregate production follows (Figure 5). The growth phase makes room for an expansion of firms' net worth, as shown in the upper-right plot of Figure 6. Consequently, the stock market capitalization also increases

\footnotetext{
${ }^{11}$ As explained in Section 3.2, the EPS multiplier is based on the dividend discount model with symplifing assumptions about dividend evolution and number of future cash flow to be considered for the price evaluation. Here, we add a further simplifying assumption, given that we do not discount cash flows with an interest rate that considers the stock market risk premium, but we discount the future cash flows with the risk free rate. However, a more complex calculation of the multiplier does not change the mechanism involved: the addiction of a risk premium only shifts the interest rate level used to discount cash flows, reducing the multiplier, but it does not change the fact that an interest rate reduction is associate with a multiplier growth, and vice versa. Moreover, the overall value of the multiplier can be enlarged/reduced considering other factors, such as a the number of discounted future cash flows.
} 
Figure 5: Monetary policy expansion at time 600. Red thick line for the baseline model and black thin line for the "Multiplier" model.

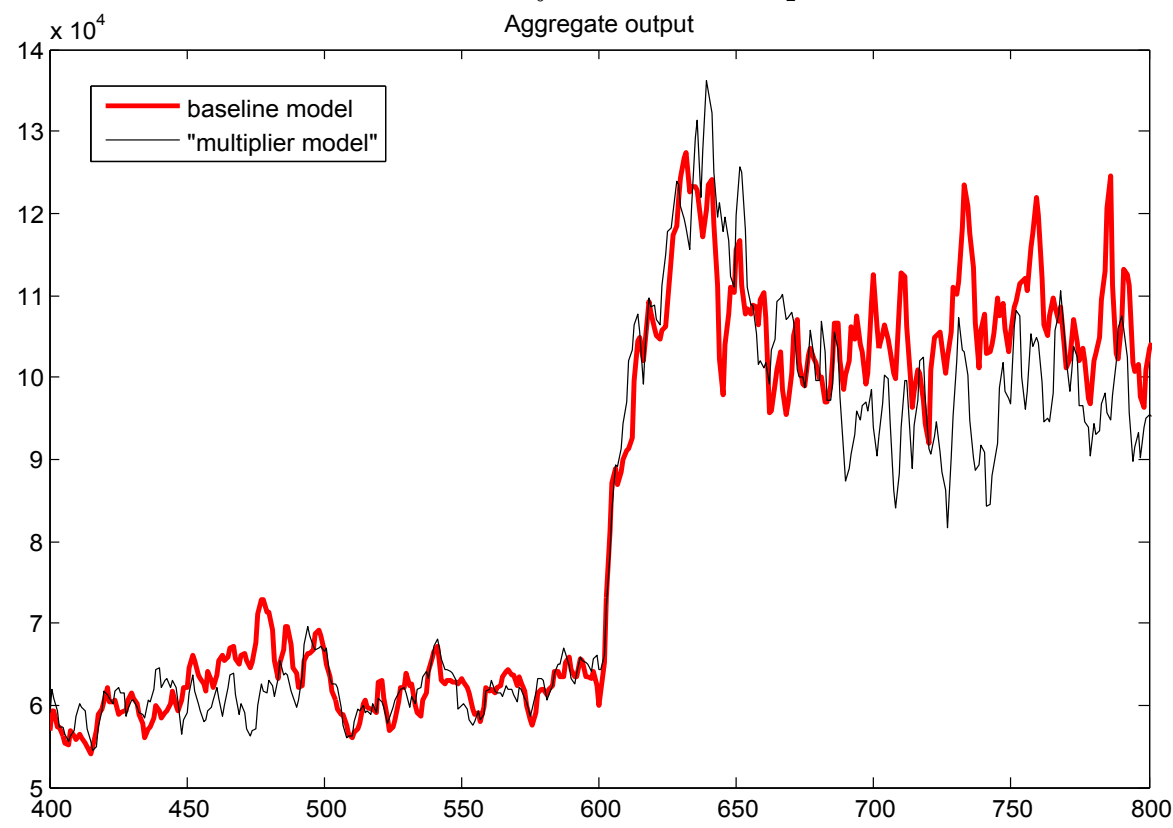

(Figure 6 upper-left plot), triggering the initially positive effect of the stock market accelerator: the DD reduces, therefore the interest rates further lower. However, after a while, the higher levels of leverage and capitalization ratio enlarge the financial accelerator mechanisms, making the economic system more volatile: more firms and banks go bankrupt, reducing the overall wealth. When deciding monetary policy changes, central banks should consider this counteracting effect due to the instability caused by the increased financial accelerator.

These mechanisms are even stronger when the stock market multiplier depends on the interest rate. In this model, the interest rate cut implies a strong stock market growth, and the capitalization ratio largely increases (upper-left panel of Figure 6), enlarging the stock market accelerator. Indeed, when the interest rate reduces, the stock market multiplier increases from 23.1 to 32.8 (while in the baseline model it is fixed at 20) and the stock market becomes more volatile. In practice, the initial expansion is a bit stronger compared to the baseline case, thanks to the growth of the stock market. However, the medium run overall benefits on aggregate production (Figure 5) are even of a minor magnitude. In other words, the incorporation of the interest rate into the multiplier partially counteracts the expansive effect of the monetary policy too. It implies a lower net worth and a higher 
Figure 6: Monetary policy expansion at time 600. $\psi=2$. Red thick line for the baseline model and black thin line for the "Multiplier" model.
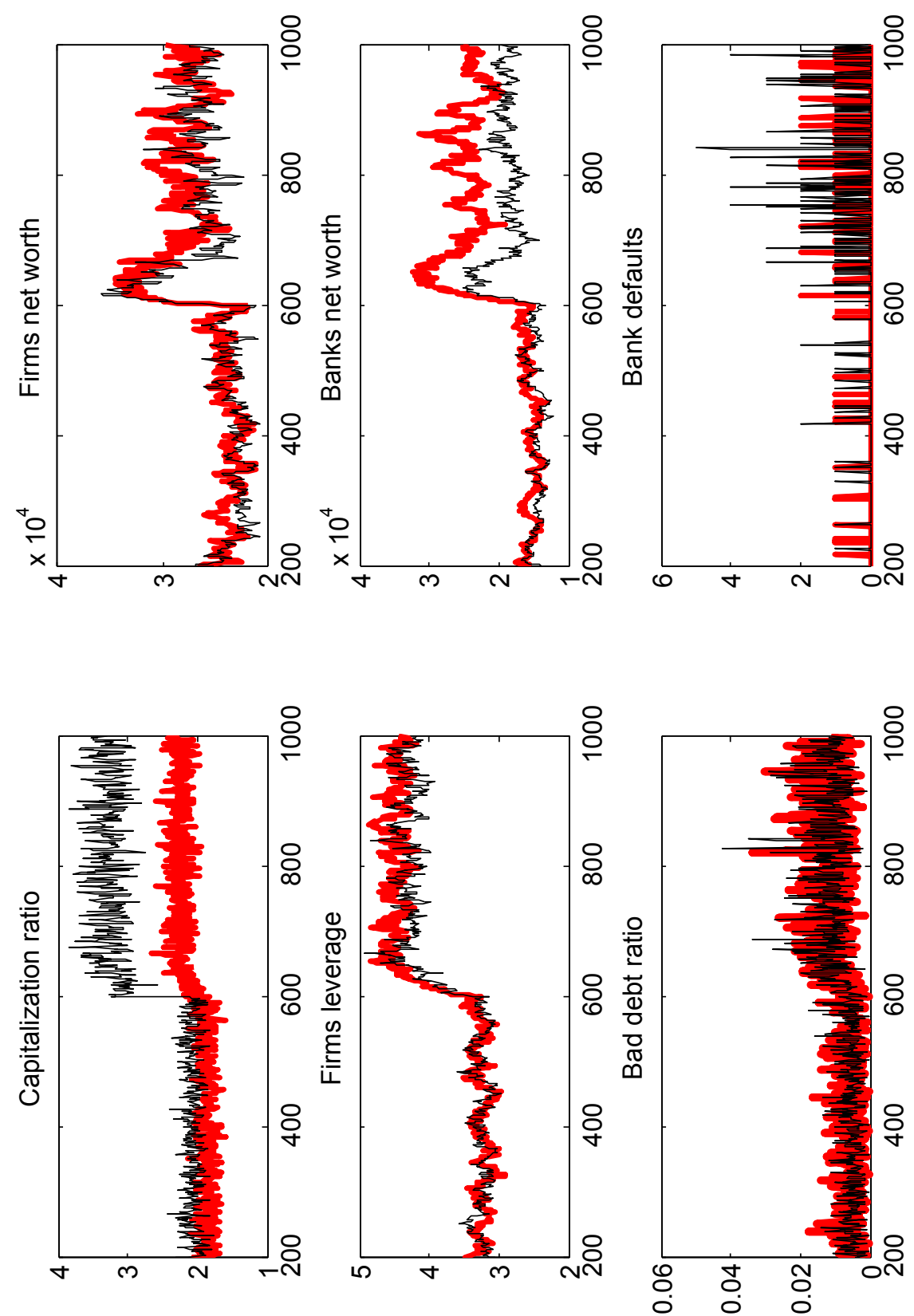
number of defaults for firms and banks.

We repeat the same experiment for very risk-prone banks in the credit market, that is with $\psi=20$, obtaining very similar results. The differences are only quantitative (see Table 2): in this case the monetary policy is more effective on the aggregate production, because the banking system strongly transmits the monetary policy impulse to the real economy.

Table 2: Aggregate variables change as a consequence of a monetary policy expansion $\left(r C B_{1-600}=3 \%, r C B_{601-1000}=1 \%\right)$. We refer to "Base" as the baseline model and to "Mult" as the model with variable EPS multiplier. The $\Delta$ is the difference between the value (average or standard deviation) of the variable calculated in period $t=601-1000$ and the value calculated in period $t=201-600$.

\begin{tabular}{l|c|c|c|c} 
Variable & $\Delta$ Base, $\psi=2$ & $\Delta$ Mult, $\psi=2$ & $\Delta$ Base, $\psi=20$ & $\Delta$ Mult, $\psi=20$ \\
\hline Average aggregate production & +23196 & +18212 & +50954 & +48371 \\
Growth rate volatility & $+0.95 \%$ & $+1.19 \%$ & $+1.53 \%$ & $+2.18 \%$ \\
Average leverage & +1.20 & +1.02 & +2.19 & +2.31 \\
Leverage volatility & +0.11 & +0.12 & +0.30 & +0.37 \\
Average bad debt ratio & $+0.58 \%$ & $+0.64 \%$ & $+0.50 \%$ & $+0.58 \%$ \\
Average bank defaults & +0.16 & +0.43 & +0.29 & +0.63
\end{tabular}

Thus, if the monetary expansion is done when banks are risk-prone, for instance in a small downturn of the business cycle, it can exploit much of its expected positive effects, while if it is done during a big financial crisis, it is probably less useful. However, as Table 2 highlights, when banks are more risk-prone the interest rate reduction also enlarges the economic volatility and the banking system fragility. Probably, it is not by chance that the financial crisis started in 2007-2008, at the end of a quite long period characterized by very low interest rates, with banks taking increasing risk (not only in the credit market). Moreover, the monetary policy expansion applied after the beginning of the crisis were dampened by the increased banks risk aversion.

Nowadays, Central Banks operate monetary policy measures even stronger than the short term interest rates reduction. Indeed, unconventional monetary policies, such as the quantitative easing measure, aimed at long term interest rates reduction, but also at financial markets prices growth. Therefore, the instability caused by the increased financial accelerator, also related to the risk of a growing bubble on financial asset prices, has to be carefully considered by Central Banks. For instance, the unconventional monetary policies implemented by the Federal Reserve push the Dow Jones Industrial index at its historical maximum in 2015, while the Bank of Japan interventions drive the Nikkei 225 index at its maximum in the last 10 years, even 
if the real economies of these countries are not performing as well as their stock markets.

However, for a deeper analysis of the unconventional monetary policy easing effects, our setting has to be further improved in order to consider:

- the demand growth due to: (i) the wealth effect on families related to stock market growth, with consequent consumption increase, (ii) the exchange rate depreciation with consequent export increase;

- the presence of a primary stock market for firms. In this case a growing stock market can help firms to issue new stocks in order to recapitalize and to reduce leverage, while in our model a stock market boom is associated with lower interest rates and higher leverage;

- the portfolio choices by investors and banks.

Nevertheless, even if the first item surely improves the effectiveness of monetary policy, also for this aspect the volatility of the stock market has to be considered, for instance, to determine the wealth effect on households. About the second item, we recall that the growing equity capitalization can be also associated with a growing debt, in order to keep the leverage around its target as explained by the already cited Dynamic Trade-Off theory, and this mechanism is the basis of the present study. Moreover, the secondary stock market transaction volume is much bigger than the primary stock market volume and a secondary market growth can divert wealth from real economy financing to financial speculation, that can also increase the banking system risks and its fragility. Therefore, the related portfolio choice modeling has to be enhanced very carefully in future works.

\section{Conclusions}

In this paper we add the presence of the stock market to a framework similar to the agent based model of Riccetti et al. (2013). The stock market values influence the distance-to-default, used to evaluate firms' financial soundness and, thus, to set the interest rates charged by banks to them. The presence of the stock market enriches the positive feedback mechanism of the Financial Accelerator, that is now threefold:

1. leverage accelerator. Negative shocks on firms' output make banks less willing to loan funds and firms less willing to invest in projects with lower expected profits (mechanism represented by increased interest rates charged by banks and risk averse firms characterized by 
a capital structure modeled with the dynamic trade-off theory), hence firms might reduce their investment and this leads again to lower output;

2. stock market accelerator. This is the most important innovation of the paper. A firm that experiences a lower profit, has a decreasing capitalization on the stock market; thus DD reduces and banks ask a higher interest rate. The increased interest rate further reduces the profit and the firm's willingness to enlarge its debt in order to expand investments, amplifying the leverage financial accelerator;

3. network-based accelerator. Bankruptcies deteriorate banks' financial condition thus leading to higher interest rates to all borrowers (Stiglitz and Greenwald, 2003, p.145). This further increases the weakness of the whole non-financial sector. Thus, the presence of a credit network may produce an avalanche of firm bankruptcies, in another vicious circle that can make banks go bankrupt too.

The first two mechanisms are the trigger of the financial accelerator, the third makes possible that an idiosyncratic shock creates an extended/global crisis without the need of a systemic shock.

In this framework, we find some interesting results, besides confirming some already found in Delli Gatti et al. (2010) and Riccetti et al. (2013), such as the emergent right-skew distribution of firms' and banks' size even if all firms start from the same conditions.

An important result is that if banks consider the firms' stock market value in evaluating the distance-to-default, the economy can benefit till the influence of the stock market is limited. If the stock market impact becomes too relevant, its volatility could damage the real economy. When the stock market impact is strong, an increase of the stock market volatility, for instance caused by a stock market multiplier rise, is widely influent in worsening the performance of the real economy, because it enlarges the stock market financial accelerator.

A very important implication for monetary policy is that when the policy rate decreases (the opposite holds for a policy rate tightening) a short-run expansion of aggregate production follows, but it is partially counteracted by the increasing financial accelerator that enlarges aggregate production volatility and banks' financial fragility. Central Banks should consider this counteracting effect when deciding monetary policy changes.

This result is even stronger in the simulation in which the stock market multiplier is affected by the interest rate level, as really happens because investors discount the future cash flows (such as dividends) at a lower rate 
(and practically the low profitability of monetary and bond products results in a liquidity inflow into the stock market). Indeed, when the stock market multiplier increases as a consequence of an interest rate decline, the effects on aggregate production is of a minor magnitude due to the even stronger stock market financial accelerator. Thus, the incorporation of the interest rate into the multiplier also counteracts the expansive effect of the monetary policy on the real economy in the medium term.

As explained in the previous Section, the model has to be further developed. However, as illustrated in the Introduction, beyond the specific conclusions of our simulations and their use in order to evaluate the effects of the monetary policy, the paper contribution to the existing literature is twofold:

- theoretically, we describe a triple financial accelerator, adding the "stock market accelerator";

- methodologically, we insert in an agent-based computational framework some simple mechanisms, well known in the mainstream literature, which are able to describe some empirical features such as the relationship between profits and stock market values or the relationship between monetary policy and stock market values.

Acknowledgments: We are grateful for helpful comments and suggestions to participants in the "Wolpertinger Conference 2014", at Università Cattolica del Sacro Cuore, Milan, September 4-6 2014, and to participants in the "17th Annual Workshop on Economic Heterogeneous Interacting Agents" (WEHIA), at University of Pantheon-Assas, Paris II, June 21-23 2012, where an earlier version of the paper was presented. Authors acknowledge the financial support from the European Community Seventh Framework Programme (FP7) under Socio-economic Sciences and Humanities, grant agreement no.FP7-ICT-255987 (FOC-II), and grant agreement no. FP7-ICT-611875 (SYMPHONY), and from Sapienza Università di Roma (for the research project "Modelli ad agenti che rappresentino le interazioni tra economia reale e finanza"). The usual disclaimer applies.

\section{References}

[1] Bargigli, L., Gallegati, M., Riccetti, L., \& Russo, A. (2014). "Network analysis and calibration of the "Leveraged network-based financial accelerator"”, Journal of Economic Behavior \& Organization, 99, 109-125. 
[2] Bernanke, B., \& Gertler, M. (1989). "Agency costs, net worth and business fluctuations", American Economic Review, 79, 14-31.

[3] Bernanke, B., \& Gertler, M. (1990). "Financial fragility and economic performance", Quarterly Journal of Economics, 105, 87-114.

[4] Bernanke, B., \& Gertler, M. (1995). "Inside the Black Box: The Credit Channel of Monetary Transmission", Journal of Economic Perspectives, $9(4), 27-48$.

[5] Bernanke, B., Gertler, M., \& Gilchrist, S. (1999). "The financial accelerator in a quantitative business cycle framework". In: J. Taylor, \& M. Woodford (Eds.), Handbook of Macroeconomics, Vol. 1 (pp.1341-1393). Amsterdam: North Holland.

[6] Campbell, J.Y., \& Taksler, G.B. (2003). "Equity Volatility and Corporate Bond Yields", Journal of Finance, 63, 2321-2349.

[7] Delli Gatti, D., Gallegati, M., Greenwald, B., Russo, A., \& Stiglitz, J.E. (2010). "The financial accelerator in an evolving credit network", Journal of Economic Dynamics and Control, 34(9), 1627-1650.

[8] Flannery, M.J., \& Rangan, K.P. (2006). "Partial adjustment toward target capital structures", Journal of Financial Economics, 79(3), 469506.

[9] Frank, M.Z., \& Goyal, V.K. (2008). "Tradeoff and Pecking Order Theories of Debt", In: Espen Eckbo (Eds.), The Handbook of Empirical Corporate Finance (Vol. 2, Chap. 12, pp. 135202). Amsterdam: Elsevier.

[10] Frank, M.Z., \& Goyal, V.K. (2015). "The Profits-Leverage Puzzle Revisited", Review of Finance, 19(4), 1415-1453.

[11] Gordon, M.J. (1959). "Dividends, earnings and stock pricings", Review of Economics and Statistics, 41(2), 99-105.

[12] Greenwald, B., \& Stiglitz, J.E. (1993). "Financial market imperfections and business cycles", Quarterly Journal of Economics, 108, 77-114.

[13] Merton R.C. (1974). "On the Pricing of Corporate Debt: the Risk Structure of Interest Rates", Journal of Finance, 29, 449-470.

[14] Riccetti, L., Russo, A., \& Gallegati, M. (2013). "Leveraged NetworkBased Financial Accelerator", Journal of Economic Dynamics and Control, 37(8), 1626-1640. 
[15] Tedeschi, G., Iori, G., \& Gallegati, M. (2012). "Herding Effects in Order Driven Markets: The Rise and Fall of Gurus", Journal of Economic Behavior \& Organization, 81, 82-96. 